\title{
Complex percutaneous coronary intervention for unprotected distal left main bifurcation lesion in a patient with cardiac allograft vasculopathy
}

\author{
Boško Skorić*, Maja Čikeš, Jana Ljubas, Željko Baričević, Davor Miličić \\ University of Zagreb School of Medicine, University Hospital Centre Zagreb, Zagreb, Croatia
}

\begin{abstract}
Introduction: Cardiac allograft vasculopathy (CAV) is a progressive form of coronary disease that defines the long term prognosis in heart transplant patients. The mortality of surgical revascularization in post-transplant patients is very high. Percutaneous coronary intervention $(\mathrm{PCl})$ has a relatively low periprocedural mortality and high acute angiographic success, but still high restenosis rate and poor long-term results. Bypass surgery (CABG) is considered the gold-standard for unprotected left main coronary artery (LMCA) disease in non-transplant patients, especially with the distal bifurcation lesion. Optimal $\mathrm{PCl}$ techniques are needed to improve the results and complex double kissing crush technique seems to be promising.
\end{abstract}

Case Report: We present a case of a 27-year-old patient who received heart transplant at the age of 24. During the second post-transplant year, he developed acute inferior ST-elevation myocardial infarction and primary $\mathrm{PCl}$ of RCA was performed. An eccentric LMCA stenosis with an involvement of large ramus intermedius (RI) and almost occluded, minor left circumflex (LCX) were detected on control an-

Received: $27^{\text {th }}$ Apr 2014

*Address for correspondence: Klinički bolnički centar Zagreb, Kišpatićeva 12, HR10000 Zagreb, Croatia.

Phone: +385-95-3959-910

E-mail: bskoric3@yahoo.com gio. We decided to perform $\mathrm{PCl}$ on this complex lesion with double kissing crush technique. Two wires were positioned distally to the lesions in both the LAD and ramus intermedius (RI). A stent was positioned in the RI with few proximal millimeters protruding into the LMCA, a balloon with a length long enough to cover the protruding stent segment was concurrently positioned in the LAD. The RI stent was deployed. The SB stent-balloon and wire were removed. The balloon in LAD was then inflated at a high pressure to crush the protruding RI stent. The RI ostium was rewired and dilated with a balloon. The bifurcation was then kissed with two balloons. Afterwards, a stent was deployed in the LMCA toward LAD at a high pressure. The RI ostium was rewired for the second time through the LMCA stent strut and dilated with a balloon at a high pressure. The final kissing balloon inflation in the bifurcation was performed at a high pressure and finished with proximal optimization of LMCA. The control angio performed 6 months later showed no signs of restenosis.

Summary: The treatment of CAV is very challenging and while $C A B G$ remains a poor revascularization option, $\mathrm{PCl}$ of complex lesions such as those of LMCA require optimal technique to reduce the incidence of adverse cardiac events and prevent further graft deterioration.

KEYWORDS: cardiac allograft vasculopathy, percutaneous coronary intervention.

CITATION: Cardiol Croat. 2014;9(5-6):176.

\section{Literature}

1. Lee MS, Finch W, Weisz G, Kirtane AJ. Cardiac allograft vasculopathy. Rev Cardiovasc Med. 2011;12(3):143-52. 